\title{
Negative Inotropic Effect of Nifedipine in the Immature Rabbit Heart Is Due to Shortening of the Action Potential
}

\author{
ANITA GO, SHEKHAR SRIVASTAVA, LEON COLLIS, WILLIAM A. COETZEE, AND \\ MICHAEL ARTMAN \\ Department of Pediatrics, Pediatric Cardiology Molecular and Cellular Research Laboratories, New York \\ University School of Medicine, New York, NY 10016
}

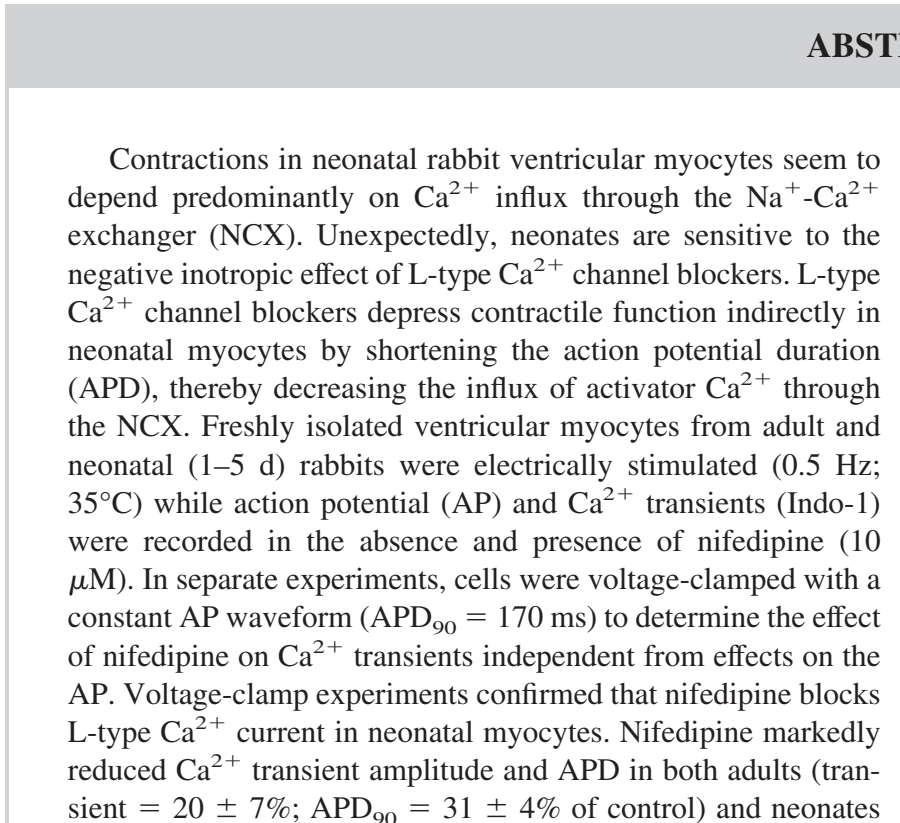

Mechanisms of excitation-contraction (EC) coupling and relaxation in mammalian ventricular myocytes undergo major changes during postnatal development $(1,2)$. In mature myocardial cells, influx of calcium via L-type calcium channels triggers the intracellular release of calcium from the sarcoplasmic reticulum (SR), leading to activation of the contractile proteins (3). In contrast, calcium-induced calcium release plays a minor role in the neonatal rabbit heart. Neonatal myocytes are much more dependent on calcium influx across the sarcolemma through the sodium-calcium exchanger (NCX) and/or calcium channels as the source(s) of activator calcium for contraction. $(1,2,4,5)$

Received March 23, 2004; accepted August 2, 2004.

Correspondence: Michael Artman, M.D., Pediatric Cardiology, FPT Suite 9-U, New York University School of Medicine, 530 First Avenue, New York, NY 10016; e-mail: michael.artman@med.nyu.edu

This work was supported by the Seventh Masonic District Association, Inc., and the National Institutes of Health (HD 39988 and HL 58899 awarded to M.A.).

DOI: 10.1203/01.PDR.0000150798.83920.5A (transient $=38 \pm 10 \% ; \mathrm{APD}_{90}=57 \pm 6 \%$ of control). When the AP was held constant by voltage clamping, nifedipine significantly reduced the amplitude of $\mathrm{Ca}^{2+}$ transients in adults $(27$ $\pm 9 \%$ of control) but had no effect on $\mathrm{Ca}^{2+}$ transient amplitude in neonatal myocytes. These results are consistent with the concept that immature ventricular myocytes are less reliant on L-type calcium channels and are more dependent on NCX for contraction. The negative inotropic effect of L-type $\mathrm{Ca}^{2+}$ channel blockers in neonates is attributable to shortening of the AP.

(Pediatr Res 57: 399-403, 2005)

AP, action potential
APD, action potential duration
EC, excitation-contraction
I $_{\text {Ca }}$, L-type calcium current
NCX, sodium-calcium exchange
SR, sarcoplasmic reticulum

It was demonstrated previously that NCX protein expression and functional NCX activity were highest in late fetal and early neonatal rabbits and declined postnatally to adult levels by 2-3 wk of age $(6,7)$. These observations are consistent with more recent studies suggesting that the major source of calcium influx in neonatal myocytes is through the $\operatorname{NCX}(5,8)$. In contrast, L-type calcium current $\left(\mathrm{I}_{\mathrm{Ca}}\right)$ density is relatively small in immature rabbit myocytes, and $\mathrm{I}_{\mathrm{Ca}}$ may not contribute significantly to calcium influx in newborns $(5,9)$. Indeed, when $\mathrm{I}_{\mathrm{Ca}}$ is blocked and the SR is disabled experimentally, NCX is sufficient for normal contraction and relaxation in neonatal myocytes $(4,8)$.

Despite the observations that newborn myocytes rely predominately on $\mathrm{NCX}$ for contraction and that $\mathrm{I}_{\mathrm{Ca}}$ may play a relatively minor role in triggering $\mathrm{SR}$ calcium release, newborns are exquisitely sensitive to the negative inotropic effects of calcium channel blockers (10). Previous studies using voltage-clamp techniques provide some insights into this apparent paradox. Klitzner et al. (11) demonstrated that voltage clamp- 
ing reduced the depression of tension development produced by diltiazem in right ventricular papillary muscles isolated from immature rabbits. Furthermore, voltage clamping immature rabbit ventricular myocytes with long square-wave pulses prevented depression of cell shortening by nifedipine (5). We therefore hypothesized that the negative inotropic effects of calcium channel blockers in neonates might be due to shortening of the action potential (AP). If this concept is correct, then the shortened AP will result in less time for NCXmediated calcium influx and thereby will reduce the amplitude of the calcium transient and produce a negative inotropic effect.

The purpose of the present studies was to determine the effects of nifedipine on AP configuration and calcium transient amplitude in neonatal myocytes. Our experiments in single isolated myocytes measured the effects of nifedipine on AP configuration and calcium transients that have not been reported in previous studies using papillary muscles (11) or isolated myocytes (5). We speculated that if $\mathrm{I}_{\mathrm{Ca}}$ does not trigger SR calcium release or contribute significantly to direct activation of the contractile proteins, then voltage clamping neonatal cells with a fixed AP would prevent the depression of calcium transient amplitude by nifedipine. This approach therefore provides new insights into the roles of $\mathrm{I}_{\mathrm{Ca}}, \mathrm{NCX}$, and AP configuration in modulating the amplitude of the calcium transient in neonatal ventricular myocytes.

\section{METHODS}

Animals. The investigation was performed in accordance with the Guide for the Care and Use of Laboratory Animals published by the National Institutes of Health (Publication No. 85-23, revised 1996). The study was approved by the Institutional Animal Care and Use Committee of New York University School of Medicine.

Cell isolation. Ventricular myocytes were isolated from the hearts of newborn (1-5 d old; either sex) and adult (3-4 mo old male) New Zealand White rabbits by enzymatic dissociation. After pentobarbital overdose (60 $\mathrm{mg} / \mathrm{kg}$ ) and heparin (500 IU/kg) injection (intraperitoneally in newborns and intravenously in adults), the heart was rapidly excised and mounted on a Langendorff apparatus and perfused initially with oxygenated Tyrode's buffer solution, followed by nominally $\mathrm{Ca}^{2+}$-free Tyrode's buffer solution. Collagenase (Worthington Type II) and protease (Sigma Chemical Co. Type XIV) dissolved in $\mathrm{Ca}^{2+}$-free Tyrode's were subsequently perfused with an ageappropriate concentration for $15 \mathrm{~min}$ in adults and $5 \mathrm{~min}$ in newborns. The enzyme concentrations for adults were collagenase $420 \mathrm{U} / \mathrm{mL}$ and protease $0.44 \mathrm{U} / \mathrm{mL}$ and for newborns were collagenase $42 \mathrm{U} / \mathrm{mL}$ and protease 0.04 $\mathrm{U} / \mathrm{mL}$.

After the enzyme treatment, the heart was perfused for an additional 5-min period with $\mathrm{Ca}^{2+}$-free Tyrode's solution. The left ventricle was removed and cut into small pieces. The tissue fragments were placed in a cell-storage solution (see "Solutions"), where they were gently agitated to disperse single ventricular cells, which were stored at room temperature until use. All experiments were performed within $10 \mathrm{~h}$ of cell isolation. Experiments were performed at $35^{\circ} \mathrm{C}$

Solutions. Tyrode's solution consisted of (in mM) $137 \mathrm{NaCl}, 5.4 \mathrm{KCl}, 10$ HEPES, $1 \mathrm{MgCl}_{2}, 0.33 \mathrm{NaH}_{2} \mathrm{PO}_{4} \mathrm{H}_{2} \mathrm{O}, 1.8 \mathrm{CaCl}_{2}$, and 10 glucose ( $\mathrm{pH}$ titrated to 7.4 with $\mathrm{NaOH}) . \mathrm{Ca}^{2+}$-free Tyrode's has the same composition as Tyrode's buffer solution but without added calcium. Cell storage (KB solution, in $\mathrm{mM}$ ) was 20 Taurine, $50 \mathrm{C}_{5} \mathrm{H}_{9} \mathrm{NO}_{4}, 10$ HEPES, 0.5 EGTA acid, $3 \mathrm{MgSO}_{4}, 30$ $\mathrm{KH}_{2} \mathrm{PO}_{4}, 30 \mathrm{KCl}$, and $78 \mathrm{KOH}$ ( $\mathrm{pH}$ titrated to 7.2 with $\mathrm{KOH}$ ). The bath solution used for measurement of $\mathrm{I}_{\mathrm{Ca}}$ contained (in mM) 140 TEA, 50 niflumic acid, $6 \mathrm{CsCl}, 5 \mathrm{HEPES}, 2 \mathrm{CaCl}_{2}, 1 \mathrm{MgCl}_{2}$, and 10 glucose ( $\mathrm{pH}$ adjusted to 7.4 with TEA-OH).

Pipette solution for current clamp studies (in $\mathrm{mM}$ ) was $110 \mathrm{~K}^{+}$-aspartate, $20 \mathrm{KCl}, 10 \mathrm{HEPES}, 5$ sodium ATP, $1 \mathrm{MgCl}_{2}$, and $1 \mathrm{CaCl}_{2}$ [pH adjusted to 7.2 with $\mathrm{KOH}$ and amphotericin $(120 \mu \mathrm{g} / \mathrm{mL})$ was freshly added before experimentation]. Pipette solution for voltage-clamp studies (in $\mathrm{mM}$ ) was 130 $\mathrm{K}^{+}$-glutamate, $9 \mathrm{KCl}, 10 \mathrm{NaCl}, 1 \mathrm{MgCl}_{2}, 5 \mathrm{Mg}$-ATP, and $10 \mathrm{HEPES}(80 \mu \mathrm{M}$ Indo- $1 \mathrm{~K}^{+}$salt was added, $\mathrm{pH}$ adjusted to 7.2 with $\mathrm{KOH}$ ). Pipette solution for recording $\mathrm{I}_{\mathrm{Ca}}$ (in $\mathrm{mM}$ ) was $125 \mathrm{CsCl}, 20$ HEPES, $10 \mathrm{Mg}$-ATP, 5 BAPTA (tetracesium salt), and 0.3 GTP (tris salt), buffered to 7.2 with $\mathrm{CsOH}$.

Nifedipine (Sigma Chemical Co., St. Louis, MO) was prepared as a $10-\mathrm{mM}$ stock solution dissolved in DMSO and was diluted in the bath solution for the experiment. The final concentration of DMSO was $0.1 \%$.

Current-clamp experiments. Current-clamp experiments were performed in the whole-cell perforated patch configuration by using an Axopatch 200A patch-clamp amplifier (Axon Instruments, Foster City, CA). Isolated myocytes were loaded with $10 \mu \mathrm{M}$ of Indo-1 acetoxymethylester dye for $10 \mathrm{~min}$ and then washed for 20-30 min in KB solution before study. Pipettes were pulled from borosilicate glass with resistance of 1.6-2.2 $\mathrm{M} \Omega$ when filled with the pipette solution. A tight seal was established in normal Tyrode's solution with subsequent membrane perforation with the use of amphotericin. The cells were field-stimulated at $0.5 \mathrm{~Hz}$ at 1.5 times the threshold voltage with a pulse width of $1.8 \mathrm{~ms}$. After nulling background fluorescence, intracellular calcium transients and AP configuration were recorded at baseline and after addition of nifedipine. All recordings were made after achieving steady-state conditions. The AP duration (APD) was recorded at $0 \mathrm{mV}$ (APD 0 ) and also as the time from the onset to $90 \%$ repolarization $\left(\mathrm{APD}_{90}\right)$.

Voltage-clamp experiments. Voltage-clamp experiments were performed in the whole-cell ruptured patch configuration with the same amplifier system. Myocytes were loaded through the patch pipette $(80 \mu \mathrm{M}$ of pentapotassium salt of Indo-1) with the pipette solution. After breaking the membrane by applying brief suction to the pipette, cells were held at $-80 \mathrm{mV}$. The cells were clamped using a constant $\mathrm{AP}$ waveform $\left(\mathrm{APD}_{90}=170 \mathrm{~ms}\right)$, a waveform that is slightly longer than the normal newborn waveform but slightly shorter than that of adult. After nulling background fluorescence, intracellular calcium transient fluorescence signals were measured at baseline and after addition of nifedipine. The fluorescence signals were not calibrated for levels of intracellular calcium.

In separate experiments, $\mathrm{I}_{\mathrm{Ca}}$ was recorded in newborn ventricular myocytes to verify nifedipine-induced block of the L-type calcium current. Newborn (1-5 d) rabbit ventricular myocytes were patch-clamped in whole-cell mode. Three- to 5-M $\Omega$ pipettes were pulled from 1.5-mm (1.12 mm I.D.) borosilicate glass capillaries (World Precision Instruments, Sarasota, FL) on a DMZ Universal Puller and subsequently fire-polished. Seal and cell rupture was achieved in Tyrode's solution, and the myocytes were clamped to $-80 \mathrm{mV}$ and subsequently superfused with the modified bath solution. After $5 \mathrm{~min}$ of dialysis, cell capacitance, access resistance, and membrane seal resistance were measured using a $5-\mathrm{mV}$ step pulse at a holding potential of $-80 \mathrm{mV}$. The average cell capacitance was $18.0 \pm 2.0 \mathrm{pF}(n=8)$. Access resistances of between 2 and $10 \mathrm{M} \Omega$ were deemed adequate. Cell capacitance and series resistance thus were compensated (the latter to at least 70\%). L-type calcium currents were measured with a prepulse from -80 to $-50 \mathrm{mV}$ for $200 \mathrm{~ms}$ to inactivate any T-type calcium currents and sodium currents. A step-pulse series from -50 to $50 \mathrm{mV}$ (increments of $10 \mathrm{mV}$ at $0.1 \mathrm{~Hz}$ ) was used to establish a current-voltage (IV) plot, whereas a single pulse from -50 to $-10 \mathrm{mV}(0.05$ $\mathrm{Hz}$ ) was used to examine the time-dependent effect of nifedipine on $\mathrm{I}_{\mathrm{Ca}}$. For the IV plot, $10 \mu \mathrm{M}$ of nifedipine was applied for $2 \mathrm{~min}$ in modified bath solution before recording commenced.

Data acquisition and data analysis. In all experiments, current and voltage were measured with a patch-clamp amplifier (Axoclamp 200B; Axon Instruments). The offset potential was corrected by zeroing the potential before touching the surface of the cell with the pipette tip. During the respective solution conditions, the calculated liquid junctional potential was $16.0 \mathrm{mV}$ (pipette positive) when voltage clamping with APs or $6.8 \mathrm{mV}$ (pipette positive) when measuring $\mathrm{I}_{\mathrm{Ca}}$. Currents were low-pass filtered at $1 \mathrm{kHz}$ and acquired to hard disk at $10 \mathrm{kHz}$ (pClamp v.8.2; Axon Instruments). Bath solutions were temperature controlled with a multiline solution heater (Model TC324B; Warner Instruments, Hamden, CT). Fluorescence measurements were obtained using a Labmaster fluorescence system (Photon Technology International, Lawrenceville, NJ). The signals were filtered and recorded on a computer hard disk after digitizing at $100 \mathrm{~Hz}$ (Felix software, Photon Technology International). pClamp8 software was used to control voltage protocols and record AP waveforms.

Data are presented as mean \pm SEM. Statistical significance was determined by $t$ test for paired data. A $p<0.05$ was considered significant.

\section{RESULTS}

Current-clamp studies. To study the effect of nifedipine, we simultaneously recorded the AP and calcium transients from isolated rabbit ventricular myocytes. Data from AP recordings are summarized in Table 1 . Nifedipine $(10 \mu \mathrm{M})$ caused a significant reduction of the APD in both adult and newborn 
Table 1. Effects of nifedipine $(10 \mu M)$ on AP parameters in adult and newborn rabbit ventricular myocytes

\begin{tabular}{lccc}
\hline & Control & Nifedipine & Washout \\
\hline Adult myocytes $(n=7)$ & & & \\
APD 0 (ms) & $239 \pm 36$ & $50 \pm 11^{*}$ & $228 \pm 40$ \\
APD $_{90}(\mathrm{~ms})$ & $275 \pm 38$ & $87 \pm 17^{*}$ & $268 \pm 42$ \\
AP amplitude $(\mathrm{mV})$ & $117 \pm 4$ & $111 \pm 4$ & $113 \pm 5$ \\
RMP (mV) & $-80 \pm 1$ & $-81 \pm 2$ & $-80 \pm 1$ \\
Neonatal myocytes $(n=6)$ & & & \\
APD 0 (ms) & $82 \pm 8$ & $35 \pm 3^{*}$ & $87 \pm 11$ \\
APD $(\mathrm{ms})$ & $116 \pm 5$ & $65 \pm 6^{*}$ & $124 \pm 13$ \\
AP amplitude (mV) & $110 \pm 3$ & $105 \pm 3$ & $112 \pm 3$ \\
RMP (ms) & $-73 \pm 1$ & $-70 \pm 2$ & $-76 \pm 1$ \\
\hline
\end{tabular}

Membrane potentials were corrected using the junctional potential which was $-17 \mathrm{mV}$.

* Different from control $(p<0.05)$.

myocytes (Table 1, Fig. 1) without affecting the resting membrane potential or the AP amplitude (Table 1, Figs. 1 and 2). In summary, nifedipine shortened the APD both in adult (APD 0 $=21 \pm 4 \%$ and $\mathrm{APD}_{90}=31 \pm 4 \%$ of control) and in newborns $\left(\mathrm{APD} 0=45 \pm 6 \%\right.$ and $\mathrm{APD}_{90}=57 \pm 6 \%$ of control). The amplitudes of calcium transients were also markedly depressed in both adult (Fig. 1) and newborn (Fig. 2) myocytes (by $20 \pm 7$ and $38 \pm 10 \%$ of control, respectively). Data are summarized in Fig. 3.

Voltage-clamp studies. We also studied the effect of nifedipine on calcium transients independent of its effect on the AP. For these experiments, we controlled the membrane potential by performing voltage clamping using a prerecorded AP waveform $\left(\mathrm{APD}_{90}=170 \mathrm{~ms}\right)$ as the command voltage. Intracellular calcium transients were recorded before and after application of nifedipine. Nifedipine reduced the calcium transient amplitude significantly in adult myocytes (to $\sim 30 \%$ of control; Fig. $4 A)$. In contrast, nifedipine had little effect on calcium transients in newborn myocytes under these experimental conditions (Fig. 4B). These results are summarized in Fig. 5.

The concentration of nifedipine $(10 \mu \mathrm{M})$ used was sufficient to completely block $\mathrm{I}_{\mathrm{Ca}}$ within $2 \mathrm{~min}$, leaving residual leakage current and trace outward currents (Fig. 6A). Example currents

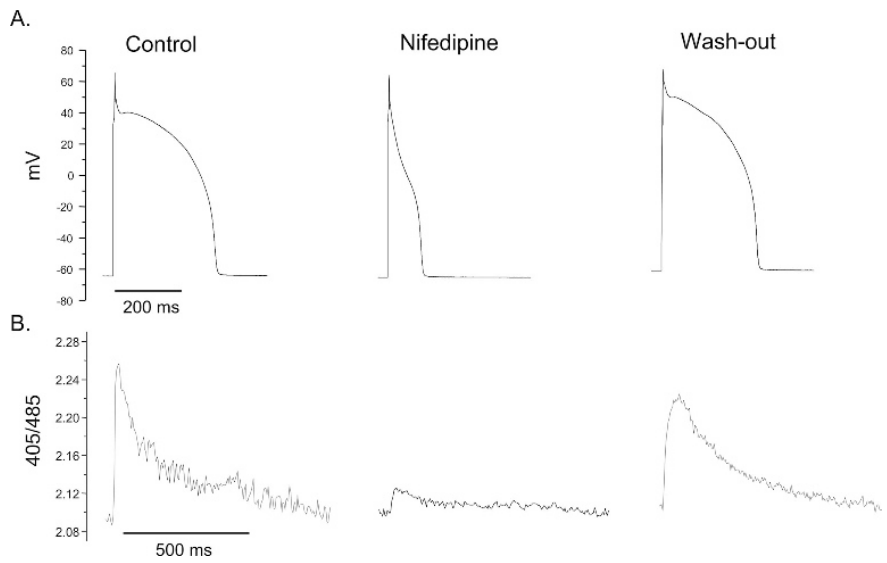

Figure 1. Effect of nifedipine on APs and intracellular calcium transients recorded under current-clamp conditions in adult rabbit ventricular myocytes. Representative recordings that were made before (control), during, and after washout of nifedipine $(10 \mu \mathrm{M})$ are shown. Nifedipine markedly reduced $\mathrm{Ca}^{2+}$ transient amplitude and APD.
A.
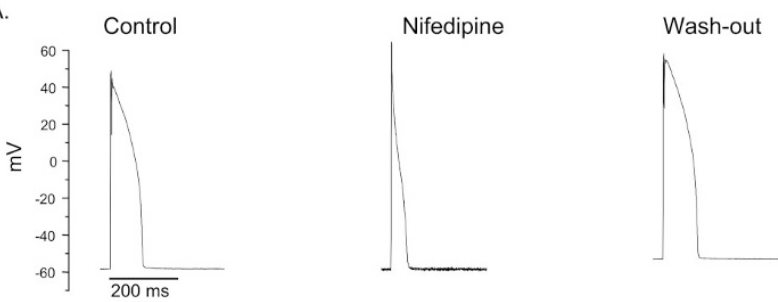

B

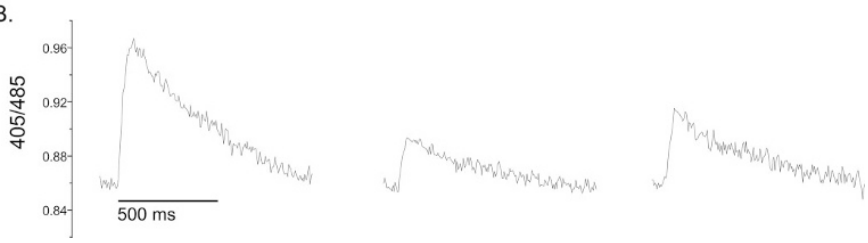

Figure 2. Effect of nifedipine on APs and intracellular calcium transients recorded under current-clamp conditions in neonatal rabbit ventricular myocytes. Representative recordings that were made before (control), during, and after washout of nifedipine $(10 \mu \mathrm{M})$ are shown. Nifedipine markedly reduced $\mathrm{Ca}^{2+}$ transient amplitude and APD.

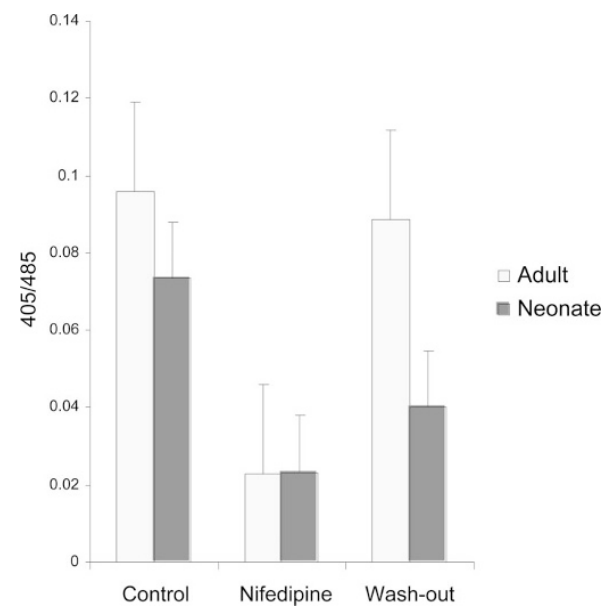

Figure 3. Summary of the effects of nifedipine $(10 \mu \mathrm{M})$ on calcium transient amplitude in current-clamped adult $(n=7)$ and neonatal $(n=7)$ rabbit ventricular myocytes before (control) and during nifedipine exposure $(10 \mu \mathrm{M})$ and after nifedipine washout. 405/485, Indo-1 emission ratio. Nifedipine significantly reduced the calcium transient amplitude of both adult and neonatal rabbit ventricular myocytes. *Different from control $(p<0.05)$.

before and after application of nifedipine are shown as insets. To verify that nifedipine inhibits $\mathrm{I}_{\mathrm{Ca}}$ in a voltage-independent manner in newborn myocytes, we performed voltage-clamp experiments using a step voltage-clamp protocol. Currents were recorded, expressed as current density by dividing by the cell capacitance, and plotted as a function of voltage to obtain IV relations (Fig. 6B). The IV curve of $\mathrm{I}_{\mathrm{Ca}}$ recorded from neonatal rabbit cardiac myocytes exhibited a standard bellshaped relation with the current peaking at $\sim-10 \mathrm{mV}$. Nifedipine $(10 \mu \mathrm{M})$ completely inhibited inward currents at all voltages.

\section{DISCUSSION}

Our data demonstrate that 1) nifedipine shortens the APD and reduces the amplitude of calcium transients in both adult and newborn ventricular myocytes, 2) nifedipine reduces the calcium transient amplitude in adult cells that are voltage- 
A.

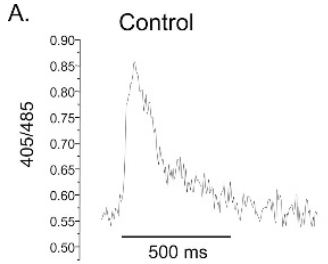

B.
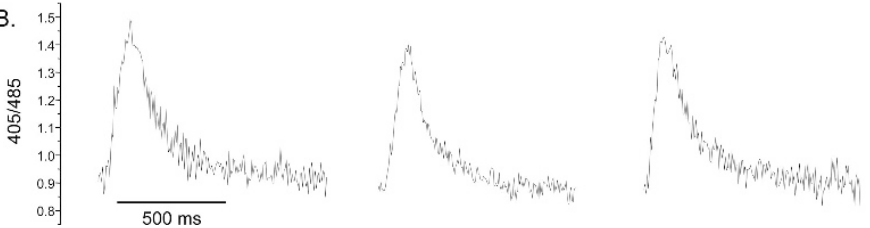

Figure 4. Effect of nifedipine on intracellular calcium transients under voltage-clamp conditions. Voltage clamping was performed using a prerecorded AP as the command waveform. Shown are data obtained from an adult $(A)$ and a neonatal $(B)$ rabbit ventricular myocyte before (control), during, and after washout of nifedipine $(10 \mu \mathrm{M})$. Nifedipine markedly reduced the amplitude of $\mathrm{Ca}^{2+}$ transients in adults but not in neonatal myocytes.

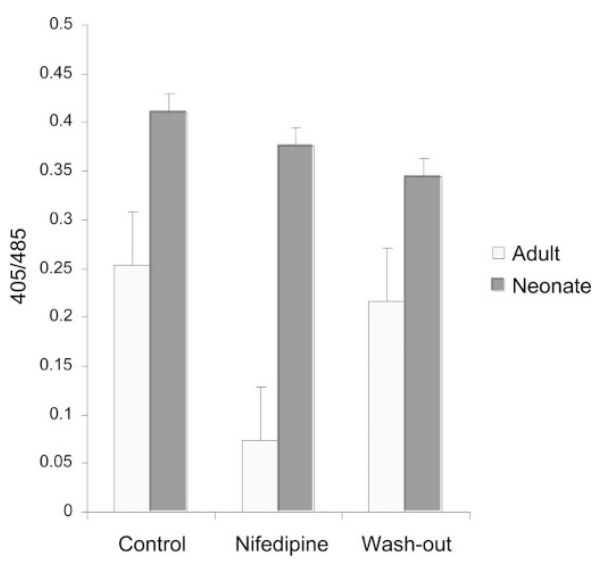

Figure 5. Summary of the effects of nifedipine $(10 \mu \mathrm{M})$ on calcium transient amplitude in voltage-clamped adult $(n=11)$ and neonatal $(n=5)$ rabbit ventricular myocytes. Nifedipine significantly reduced the amplitude of $\mathrm{Ca}^{2+}$ transients in adults but had no effect on $\mathrm{Ca}^{2+}$ transients in neonatal myocytes. $*$ Different from control $(p<0.05)$.

clamped with a constant AP waveform, and 3) nifedipine had no effect on the calcium transient in newborn myocytes when the AP was held constant.

It is well established that in the adult heart, $\mathrm{I}_{\mathrm{Ca}}$ has a major role in EC coupling by triggering SR calcium release. Inhibition of this trigger by nifedipine markedly reduces the amplitude of the calcium transient in adult myocytes, as shown by our present results in both voltage-clamp and current-clamp conditions.

Previous data demonstrated a reduced $\mathrm{I}_{\mathrm{Ca}}$ amplitude in neonatal rabbit ventricular myocytes $(5,8,12)$. The reliance on $\mathrm{Ca}^{2+}$ influx from external sources through the NCX to cause contractions in immature cardiac myocytes $(5,8,13)$ argues for a relatively smaller role for $\mathrm{I}_{\mathrm{Ca}}$ in $\mathrm{EC}$ coupling in the immature heart. We found that nifedipine, which completely blocks the $\mathrm{Ca}^{2+}$ current, had no effect on the intracellular $\mathrm{Ca}^{2+}$ transient when myocytes were voltage-clamped using a prerecorded AP. Our data presented here therefore provide direct support for the notion that $\mathrm{Ca}^{2+}$ influx via nifedipine-sensitive voltageactivated calcium channels in neonatal myocytes has little role
A.

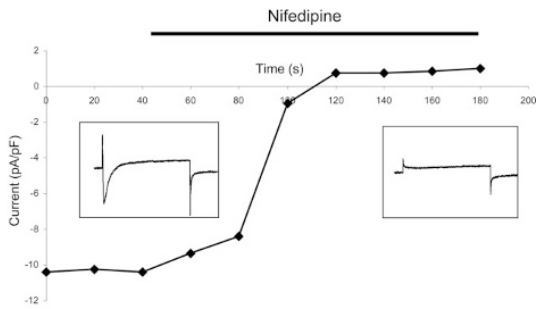

B.

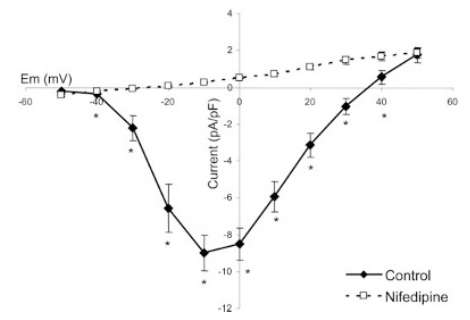

Figure 6. Nifedipine $(10 \mu \mathrm{M})$ blocks the calcium current in neonatal rabbit ventricular myocytes. (A) Representative time-step protocol demonstrates complete block of $\mathrm{I}_{\mathrm{Ca}}$ from 1 to $2 \mathrm{~min}$ after onset of application. Example current recordings are shown in insets, before and after nifedipine application. (B) An IV plot shows mean peak calcium current $(n=5)$ for each voltage step $\left(-50\right.$ to $50 \mathrm{mV}$ ) with and without nifedipine. In control, $\mathrm{I}_{\mathrm{Ca}}$ peaked at $\sim-10$ $\mathrm{mV}$, and nifedipine completely inhibited inward currents at all voltages, leaving minimal residual outward and leakage current components. *Different from control $(p<0.05)$.

in providing activator $\mathrm{Ca}^{2+}$ under basal conditions, either by directly activating contractile proteins or by triggering release of $\mathrm{Ca}^{2+}$ from internal stores.

If calcium influx through calcium channels is not sufficient to activate the contractile proteins directly or indirectly as argued above, then how does blockade of calcium channels account for the well-described negative inotropic effect of calcium channel blockers in neonates? Our data show that, under voltage-clamp conditions, nifedipine has no effect on the intracellular $\mathrm{Ca}^{2+}$ transient. However, under current-clamp conditions, when the APD is allowed to change, nifedipine strongly decreases the amplitude of the intracellular $\mathrm{Ca}^{2+}$ transient, which is consistent with the known negative inotropic effect of this class of drugs in the immature heart $(11,13)$. Several deductions can be made from these data. First, although the $\mathrm{I}_{\mathrm{Ca}}$ is small in neonatal rabbit myocytes compared with the adult $(5,8,12)$, our results demonstrate that there is an important role for the $\mathrm{I}_{\mathrm{Ca}}$ in maintaining the APD in the immature heart. However, the amount of $\mathrm{Ca}^{2+}$ influx through these channels during an AP is presumably insufficient to cause an elevation in global intracellular $\mathrm{Ca}^{2+}$. That nifedipine exerts a profound negative inotropic effect under current-clamp but not under voltage-clamp conditions suggests that the negative inotropic effect of nifedipine is due to related changes in the AP. Indeed, we found that nifedipine shortens the AP substantially in immature cardiac myocytes. The shortened plateau phase of the AP will result in less time being spent at depolarized levels, where $\mathrm{Ca}^{2+}$ influx occurs through "reverse" $\mathrm{Na}^{+}-\mathrm{Ca}^{2+}$ exchanger. This concept is in full support of our previously published data, which showed that shortening the APD under controlled experimental conditions in which the $\mathrm{Na}^{+}-\mathrm{Ca}^{2+}$ exchanger was the sole route for $\mathrm{Ca}^{2+}$ entry was 
sufficient to account for the decreased intracellular $\mathrm{Ca}^{2+}$ levels (8). Thus, by virtue of shortening the $\mathrm{AP}, \mathrm{Ca}^{2+}$ channel blockers act indirectly to decrease $\mathrm{Ca}^{2+}$ influx through the $\mathrm{Na}^{+}-\mathrm{Ca}^{2+}$ exchanger.

Limitations. Nifedipine clearly shortened the AP in both groups, but in addition, the configuration of the AP was altered in the presence of nifedipine. Thus, the responses that we attribute largely to shortening of the AP may in fact be due to changes in AP configuration, which includes a significant reduction in the total duration of the AP (see Table 1). Because calcium influx via the NCX occurs when the membrane potential exceeds the reversal potential for $\mathrm{I}_{\mathrm{NCX}}$, the duration of this period will have a major influence on calcium influx. It is difficult to quantify AP configuration, but measurement of the time period that the membrane potential exceeds $0 \mathrm{mV}$ (APD 0 ) provides a crude estimate of the effect of nifedipine on the plateau phase of the AP. Although absolute APD 0 was shorter in neonates in both the absence and the presence of nifedipine, the relative magnitude of the nifedipine effect was greater in adults (see Table 1). Our studies do not take into account potential age-related differences in localized submembrane concentrations of calcium and sodium that influence both $\mathrm{I}_{\mathrm{Ca}}$ and $\mathrm{I}_{\mathrm{NCX}}$ (14). Additional studies are required to provide a thorough understanding of the interrelationships between $\mathrm{I}_{\mathrm{Ca}}$ and $\mathrm{I}_{\mathrm{NCX}}$ and the effects of nifedipine on these interactions. Furthermore, we made no attempt to formally assess the potential role of T-type calcium channels on EC coupling in the newborn heart in these experiments. Last, rabbit ventricular myocytes were used in these experiments, and our results may not apply to other species.

Despite these limitations, it is clear that the duration of depolarization is a major determinant of calcium influx through NCX $(8,13)$. We therefore inferred that the changes in AP configuration produced by nifedipine resulted in less calcium entry through NCX. Although not tested directly, our data are entirely consistent with this concept.

\section{CONCLUSIONS}

Nifedipine significantly reduced the amplitude of the calcium transient and APD in both newborn and adult ventricular myocytes. However, if the AP is not allowed to shorten, then the depression of calcium transient amplitude by nifedipine is prevented in neonates but not in adults. The observation that calcium transients are normal in the presence of nifedipine when $\mathrm{AP}$ is maintained indicates that $\mathrm{I}_{\mathrm{Ca}}$ is not required either to trigger SR calcium release or to directly provide activator calcium in newborn rabbit myocytes. These data suggest that the major role for $\mathrm{I}_{\mathrm{Ca}}$ at birth may be related to maintaining the AP plateau, which facilitates calcium influx via the NCX. We conclude that the negative inotropic effect of L-type calcium channel blockers in the immature rabbit heart is due to shortening of the action potential.

\section{REFERENCES}

1. Artman M, Henry G, Coetzee WA 2000 Cellular basis for age-related differences in cardiac excitation-contraction coupling. Prog Pediatr Cardiol 11:185-194

2. Mahony L 1996 Regulation of intracellular calcium concentration in the developing heart. Cardiovasc Res 31:E61-E67

3. Bers DM 2002 Cardiac excitation-contraction coupling. Nature 41:198-205

4. Haddock PS, Coetzee WA, Artman M $1997 \mathrm{Na}+/ \mathrm{Ca} 2+$ exchange current and contractions measured under $\mathrm{Cl}(-)$-free conditions in developing rabbit hearts. Am J Physiol 273:H837-H846

5. Wetzel GT, Chen F, Klitzner TS $1995 \mathrm{Na}^{+} / \mathrm{Ca}^{2+}$ exchange and cell contraction in isolated neonatal and adult rabbit cardiac myocytes. Am J Physiol 268:H1723-H1733

6. Artman M 1992 Sarcolemmal $\mathrm{Na}^{+}-\mathrm{Ca}^{2+}$ exchange activity and exchanger immunoreactivity in developing rabbit hearts. Am J Physiol 263:H1506-H1513

7. Boerth SR, Zimmer DB, Artman M 1994 Steady-state mRNA levels of the sarcolemmal $\mathrm{Na}^{+}-\mathrm{Ca}^{2+}$ exchanger peak near birth in developing rabbit and rat hearts. Circ Res 74:354-359

8. Haddock PS, Artman M, Coetzee WA 1998 Influence of postnatal changes in action potential duration on Na-Ca exchange in rabbit ventricular myocytes. Pflugers Arch 435:789-795

9. Wetzel GT, Chen F, Klitzner TS $1993 \mathrm{Ca}^{2+}$ channel kinetics in acutely isolated fetal, neonatal, and adult rabbit cardiac myocytes. Circ Res 72:1065-1074

10. Artman M, Graham TP, Boucek RJ Jr 1985 Effects of postnatal maturation on myocardial contractile responses to calcium antagonists and changes in contraction frequency. J Cardiovasc Pharmacol 7:850-855

11. Klitzner TS, Chen FH, Raven RR, Wetzel GT, Friedman WF 1991 Calcium current and tension generation in immature mammalian myocardium: effects of diltiazem. J Mol Cell Cardiol 23:807-815

12. Osaka T, Joyner RW 1991 Developmental changes in calcium current of rabbit ventricular cells. Circ Res 68:788-796

13. Seguchi M, Jarmakani JM, George BL, Harding JA 1986 Effects of Ca2 + antagonists on mechanical function in the neonatal heart. Pediatr Res 20:838-842

14. Weber CR, Piacentino V 3rd, Ginsburg KS, Houser SR, Bers DM $2002 \mathrm{Na}^{+}-\mathrm{Ca}^{2+}$ exchange current and submembrane $\left[\mathrm{Ca}^{2+}\right]$ during the cardiac action potential. Circ Res 90:182-189 